\title{
Violência contra a Mulher: Ação extensionista com usuários da Atenção Primária à Saúde no município de Rio Grande-RS1
}

Débora dos Santos Rodrigues - https://orcid.org/0000-0001-7051-9682 ${ }^{2}$

Victoria Leslyê Rocha Gutmann - https://orcid.org/0000-0002-3457-7620 ${ }^{3}$

Daniele Ferreira Acosta - https://orcid.org/0000-0001-5690-1076 ${ }^{4}$

Camila Daiane Silva - https://orcid.org/0000-0002-0739-498 ${ }^{5}$

\section{RESUMO}

O tema da Violência contra a Mulher é uma importante questão de saúde pública, pois afeta a pessoa que sofre e também a sociedade. Assim, este estudo teve como objetivos relatar a realização de uma ação de extensão com homens e mulheres, usuários (as) de Estratégias Saúde da Família, para falar sobre a violência contra a mulher, e descrever a percepção dos participantes sobre a importância da ação de extensão. 0 estudo foi desenvolvido em nove Estratégias Saúde da Família do município do Rio Grande/RS, totalizando 35 participantes. Os usuários (as) demonstraram conhecimento ao citarem as formas de violência e os direitos das mulheres, como a Lei Maria da Penha. Ainda, identificaram a falta de responsabilização do Estado. Por fim, avaliaram a ação de forma positiva, sugerindo continuidade das ações também em outros espaços.

Palavras-chave: violência contra a mulher; atenção primária à saúde; extensão universitária; gênero e saúde; enfermagem.

\footnotetext{
${ }^{1}$ Este estudo faz parte de um macroprojeto de Pesquisa e Extensão, intitulado "Violência contra a mulher e o empoderamento de pessoas usuárias da Atenção Básica" aprovado em 13 de setembro de 2019 pelo Comitê de Ética em Pesquisa da Universidade Federal do Rio Grande (CEP-FURG), sob parecer no 3.573 .233 e C.A.A.E. no 18563719.2 .0000 .5324

2 Enfermeira. Universidade Federal do Rio Grande/FURG. Rio Grande, RS, Brasil. E-mail: deboraenfermagem@hotmail.com

${ }^{3}$ Enfermeira. Residente do Programa de Residência Multiprofissional em Saúde da Família da Universidade Federal do Rio Grande/FURG. Rio Grande, RS, Brasil. E-mail: victorialeslye@gmail.com

${ }^{4}$ Enfermeira. Doutora em Enfermagem. Professora do Magistério Superior da Universidade Federal do Rio Grande/FURG. Rio Grande, RS, Brasil. E-mail: nieleacosta@gmail.com

${ }^{5}$ Enfermeira. Doutora em Enfermagem. Professora do Magistério Superior da Universidade Federal do Rio Grande/FURG. Rio Grande, RS, Brasil. E-mail: camilad.silva@yahoo.com.br
} 


\title{
Violence against Women: Extension action with users of Primary Health Care in the city of Rio Grande-RS
}

\author{
ABSTRACT
}

The Violence against Women discussion is an important public health issue as it affects the person who suffers from this kind of violence and also society. Thus, this study was aimed at describing the accomplishment of an extension action with men and women that are Family Health Strategy users, in order to talk about violence against women, and at describing the participants' perception about the importance of the extension action. The study was developed in nine Family Health Strategies in the city of Rio Grande/RS, adding up to 35 participants. Users demonstrated knowledge when citing forms of violence and women's rights, such as the Maria da Penha Law. Moreover, they identified the lack of accountability of the State. Finally, they evaluated the action positively, suggesting the continuity of actions in other spaces as well.

Keywords: violence against women; primary health care; university extension; gender and health; nursing.

\section{INTRODUÇÃO}

A origem da violência tem caráter múltiplo, correlacionando condições biológicas, ambientais, históricas, psicológicas e sociais que atuam como fatores de risco ou de proteção para sua ocorrência (GUTMANN et al., 2020). Especificamente a Violência Contra a Mulher (VCM), estabelecida, na maioria das vezes, nas relações sociais entre homens e mulheres, é fundamentada em redes de poder como o patriarcado, que resultam em ameaça à integridade física, sexual, moral, patrimonial e psicológica das mulheres, tanto no âmbito privado/familiar quanto no público/trabalho (HIRT et al., 2017). Essas relações de poder são mediadas pelas desigualdades estruturais de gênero, as quais possuem como base a cultura da inferioridade feminina, impondo às mulheres uma imagem de vítima da força física masculina (MACHADO et al., 2017).

Logo, o enfrentamento à VCM é um trabalho árduo, pois exige a mudança de hábitos dos autores, das pessoas em situação de violência, dos profissionais e da 
comunidade em geral. 0 setor da saúde, especificamente a Atenção Primária à Saúde (APS), destaca-se por ser um dos primeiros locais a receber possíveis vítimas de violência. No contexto da APS, encontra-se o trabalho das Estratégias Saúde da Família (ESF), isto é, Unidades de Saúde que possuem como característica a aproximação entre os profissionais e os indivíduos do território, o que possibilita a identificação dos casos de violência, o acolhimento, o apoio, o acompanhamento e a criação de vínculo com as mulheres (FEITOSA et al., 2017).

Entretanto, existem lacunas entre a teoria e a prática que dificultam o estabelecimento do vínculo e do acolhimento efetivo das situações de violência, principalmente no que se refere à formação profissional, ainda muito voltada ao modelo biomédico. A fragilidade na formação acadêmica contribui para a fragmentação dos serviços, com encaminhamentos, muitas vezes, a outros profissionais como uma forma de "se livrar" do problema. Ainda, há outros desafios, como a falta de estrutura física e a organização do processo de trabalho nos serviços, que se caracteriza pelo excesso de demandas (MENDONÇA et al., 2020; OLIVEIRA et al., 2018).

Apesar das dificuldades, acolher estas situações é de vital importância para a qualidade e humanização da APS. Além disso, ações como visitas domiciliares, perguntas indiretas ou diretas, diálogos abertos e trabalhos voltados à educação da comunidade são ferramentas importantes na prevenção e enfrentamento da violência, uma vez que podem resultar no empoderamento das mulheres. Empoderar uma mulher significa torná-la mais forte, segura e autoconfiante. Com isso, o empoderamento feminino é um fator determinante para a mudança dos hábitos da sociedade como um todo e, principalmente, na mudança da cultura machista, sexista e patriarcal (AMARIJO et al., 2018).

Desta forma, faz-se necessário transformar o pensamento de homens e mulheres, compartilhand o o conhecimento científico de maneira clara, objetiva, simples e dialogada. Entende-se que o empoderamento da população para o enfrentamento da violência se dá por meio da problematização e da educação em saúde. Neste contexto, a Extensão universitária apresenta uma diversidade conceitual e prática que interfere expressivamente no "pensar" e no "fazer" científico, uma vez que leva informação e educação como transformadores do pensamento crítico dos indivíduos. Assim, a universidade, a partir de seus objetivos básicos de formação profissional, geração e disseminação de conhecimento, tem a função social de difundir os saberes adquiridos no Ensino e na Pesquisa através da Extensão, transpondo seus muros para prestar serviços à sociedade (CRISOSTIMO; SILVEIRA, 2017).

Nesta perspectiva, pode-se dizer que a Extensão encontra alicerce nos fundamentos de Paulo Freire, uma vez que a educação freireana ultrapassa os limites 
teóricos, pois está relacionada à maneira de compreender e refletir o mundo e, assim, poder transformá-lo de forma consciente por meio da ação coletiva (ARAÚJO et al., 2018). Desse modo, as ações extensionistas, fundamentadas na obra freireana, têm um papel diferenciado, em especial quando realizadas nas ESF, local em que se pode conhecer como as pessoas interpretam um determinado problema social e de saúde, auxiliando os profissionais a intervir de maneira coletiva, eficiente e direcionada às reais demandas dos usuários(as), tendo em vista que ainda são escassos os estudos que abordam o público que acessa os serviços.

Assim, este Estudo teve como pergunta norteadora: qual a percepção de usuários(as) de Estratégias Saúde da Família sobre a realização de uma ação extensionista acerca da violência contra a mulher? Dessa forma, objetivou-se relatar a realização de uma ação de Extensão com homens e mulheres, usuários(as) de Estratégias Saúde da Família, para falar sobre a violência contra a mulher, e descrever a percepção dos participantes sobre a importância da ação de Extensão.

\section{METOdOLOGIA}

Trata-se de um estudo de abordagem qualitativa. Para as pesquisas qualitativas, a realidade é múltipla e subjetiva, construída em conjunto entre pesquisador(a) e pesquisado(a) por meio das experiências individuais de cada indivíduo (PATIAS; HOHENDORFF, 2019). Enfatiza-se que as atividades de Extensão têm como principal objetivo e característica metodológica o envolvimento da população local nas atividades de promoção de conhecimento, bem como a participação social na avaliação e construção das Políticas Públicas (REIS; RAMOS; DÁCIO, 2017).

Esse estudo possui como fundamentação teórica a educação freireana, uma vez que ela ultrapassa os limites teóricos e baseia-se em uma educação ética, multicultural, libertadora e transformadora, voltada para uma sociedade que possui comportamentos, pensamentos e formas de ver o mundo diferentes, possuindo como base o diálogo e a reflexão crítica da realidade (ARAÚJO et al., 2018; FREIRE, 2014). Considera-se que a metodologia de Paulo Freire possibilita a aproximação dos participantes, entre si e destes com os pesquisadores, mediante o diálogo em torno das situações e temáticas levantadas. Ainda, o processo grupal como alternativa de cuidado se mostra uma estratégia que favorece as práticas de educação em saúde (ARAÚJO et al., 2018).

Assim, alguns pressupostos filosóficos e epistemológicos da educação freireana foram adotados no desenvolvimento da ação extensionista, tais como: fomento de espaços livres para diálogo e compartilhamento dos saberes, com a expressão das subjetividades 
e da experiência coletiva; atitude problematizadora e crítica acerca da temática da violência contra a mulher; e estímulo às ações de transformação da realidade, mediante a convergência entre o pensar e o atuar (FREIRE, 2014). Para colocar em prática, as pesquisadoras se alicerçaram na exposição dialogada e horizontalizada do saber, de forma que o conhecimento foi construído com o outro. Logo, a educação freireana exigiu, direta e indiretamente, a participação dos indivíduos, o que, em algumas unidades, foi um desafio e também uma dificuldade a ser superada.

Portanto, o presente estudo foi desenvolvido no município do Rio Grande, Rio Grande do Sul, o qual era coberto por 25 Unidades de Saúde ligadas à ESF. Em decorrência dos decretos municipais referentes à Covid-19, as atividades nas unidades ficaram restritas às essenciais desde março de 2020; dessa forma, o estudo foi desenvolvido em nove unidades, no período entre outubro de 2019 e fevereiro de 2020.

Participaram da condução das ações extensionistas três acadêmicas do curso de graduação de Enfermagem, além de uma professora coordenadora. As acadêmicas também eram responsáveis pelo contato com o profissional responsável de cada unidade, de forma a agendar uma data para a realização da atividade. Os instrumentos utilizados foram mídia expositiva, notebook e os materiais da coleta de dados e didáticos elaborados especificamente para esse projeto. Ao final de cada ação, era entregue uma ficha de avaliação da atividade com perguntas abertas, de forma que 35 usuários, maiores de 18 anos, preencheram-na. Destaca-se que esse quantitativo não representa o número de participantes nas ações, uma vez que alguns usuários que participaram da ação não aceitaram ou não quiseram preencher a ficha. Também participaram da ação, mas não da Pesquisa, os profissionais de diversas áreas atuantes na ESF.

A análise da atividade de Extensão foi dividida em duas etapas. Na primeira, apresenta-se uma descrição livre e detalhada das atividades, bem como das impressões e anotações no diário de campo. Na segunda etapa, apresenta-se a percepção dos participantes sobre a importância da ação de Extensão, a qual se deu por meio da análise de conteúdo na modalidade temático-categorial proposta por Laurence Bardin, caracterizada como um conjunto de técnicas de análise de comunicações que visa obter, por procedimentos sistemáticos e objetivos de transcrição do conteúdo, a inferência de conhecimentos relativos às condições de produção/recepção destas mensagens (BARDIN, 2011). A análise se organiza em três fases: a) pré-análise; b) exploração do material e o tratamento dos resultados; e c) inferência e interpretação. Adotou-se como unidade de registro os temas que emergiram das falas (BARDIN, 2011).

De forma a preservar o sigilo e anonimato, os participantes foram identificados pela palavra "Participante", seguido do número da ordem de avaliação da atividade. Este 
Estudo faz parte de um macroprojeto de Pesquisa e Extensão, intitulado "Violência contra a mulher e o empoderamento de pessoas usuárias da Atenção Básica" aprovado em 13 de setembro de 2019 pelo Comitê de Ética em Pesquisa da Universidade Federal do Rio Grande (CEP-FURG), sob parecer nํㅜ 3.573.233 e C.A.A.E. $n^{\circ}$ 18563719.2.0000.5324.

\section{RESULTADOS E DISCUSSÃO}

Apresenta-se os resultados e discussões em seis tópicos, o primeiro intitulado "Caminhos percorridos: colocando a Extensão em prática" retrata a descrição da realização da atividade de Extensão. Os seguintes quatro tópicos versam acerca das categorias resultantes da análise de conteúdo sobre a percepção dos participantes quanto à importância da ação de Extensão, intitulados "Importância da atividade e da temática abordada", "Reflexões para além da atividade de Extensão", "Sugestões para futuras atividades de Extensão" e "Dúvidas que permaneceram: clareando ideias". Por fim, a última categoria, intitulada "Avaliação das ações pelas extensionistas: aprendizagem a partir da experiência e do sentido", aborda as observações das acadêmicas sobre as atividades.

\subsection{Caminhos percorridos: colocando a Extensão em prática}

Em conjunto com a coordenadora de cada ESF era agendado uma data para a realização da ação extensionista. Um cartaz era deixado na unidade para divulgação e convite da ação aos usuários. A princípio, as datas não estavam vinculadas a nenhuma atividade presente na unidade, porém, devido à baixa adesão, foi necessário vincular as datas da ação a outras atividades desenvolvidas, como os grupos preestabelecidos dentro do serviço. Assim, além desses usuários vinculados aos grupos, a ação de Extensão era aberta a todas as pessoas que estavam presentes na data agendada e que demonstraram, voluntariamente, interesse em participar.

No dia marcado e na sala reservada, foi exposto o material didático, preparado exclusivamente para essa ação, por meio de mídia expositiva (Figura 1), além de apresentação de um vídeo introdutório sobre a temática abordada para sensibilização com as pessoas presentes. Inicialmente, após as apresentações pessoais, exibia-se um breve vídeo, de aproximadamente três minutos, intitulado "empoderamento feminino" com o objetivo de instigar a curiosidade dos participantes frente ao tema da violência. 0 vídeo retrata o empoderamento feminino e aborda brevemente sobre desigualdade de gênero, questões relativas ao patriarcado, lutas vividas e direitos adquiridos pelas mulheres ao longo dos anos. 
Figura 1 - Parte da mídia expositiva do material preparado

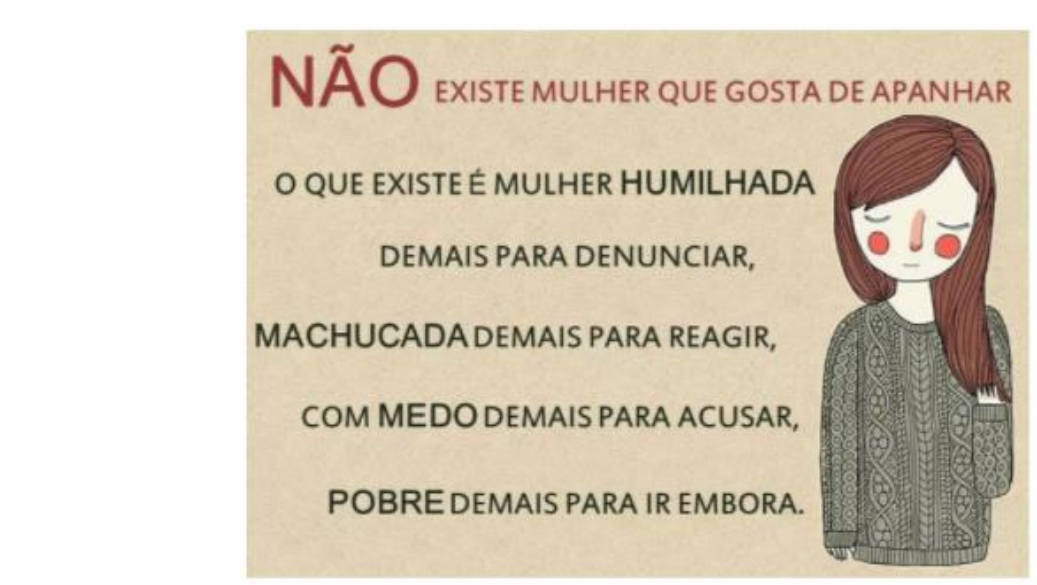

Fonte: Dados desta pesquisa. ${ }^{6}$

Após o vídeo, faziam-se alguns questionamentos aos participantes, como por exemplo "Vocês sabem o que é gênero?", "O que vocês entendem sobre patriarcado?", ou, ainda, "O que é violência para vocês?". Assim, iniciava-se a apresentação da situaçãoproblema advinda da realidade, levando-os a refletir sobre ela para, na sequência, reconhecê-la (ARAÚJO et al., 2018). Após, apresentavam-se as mídias expositivas. Com elas, foram abordados temas como patriarcado, gênero, violência física, sexual, moral, patrimonial, psicológica, leis em defesa das mulheres, formas de denúncia, locais de ajuda e auxílio às vítimas, entre outras que porventura surgiam (Figura 2). Destaca-se que à maneira como os participantes são colocados em círculo viabiliza a dialogicidade no processo de construção do saber coletivo, compartilhado e contextualizado, de forma que o conhecimento não é transmitido, mas construído em ações cuja propagação não é verticalizada e, sim, compartilhada de forma linear (ARAÚJO et al., 2018; MORAES; FARIA; FONSECA, 2019).

\footnotetext{
${ }^{6}$ Disponível no link do YouTube https://www.youtube.com/watch?v=6RSc_XYezig
} 


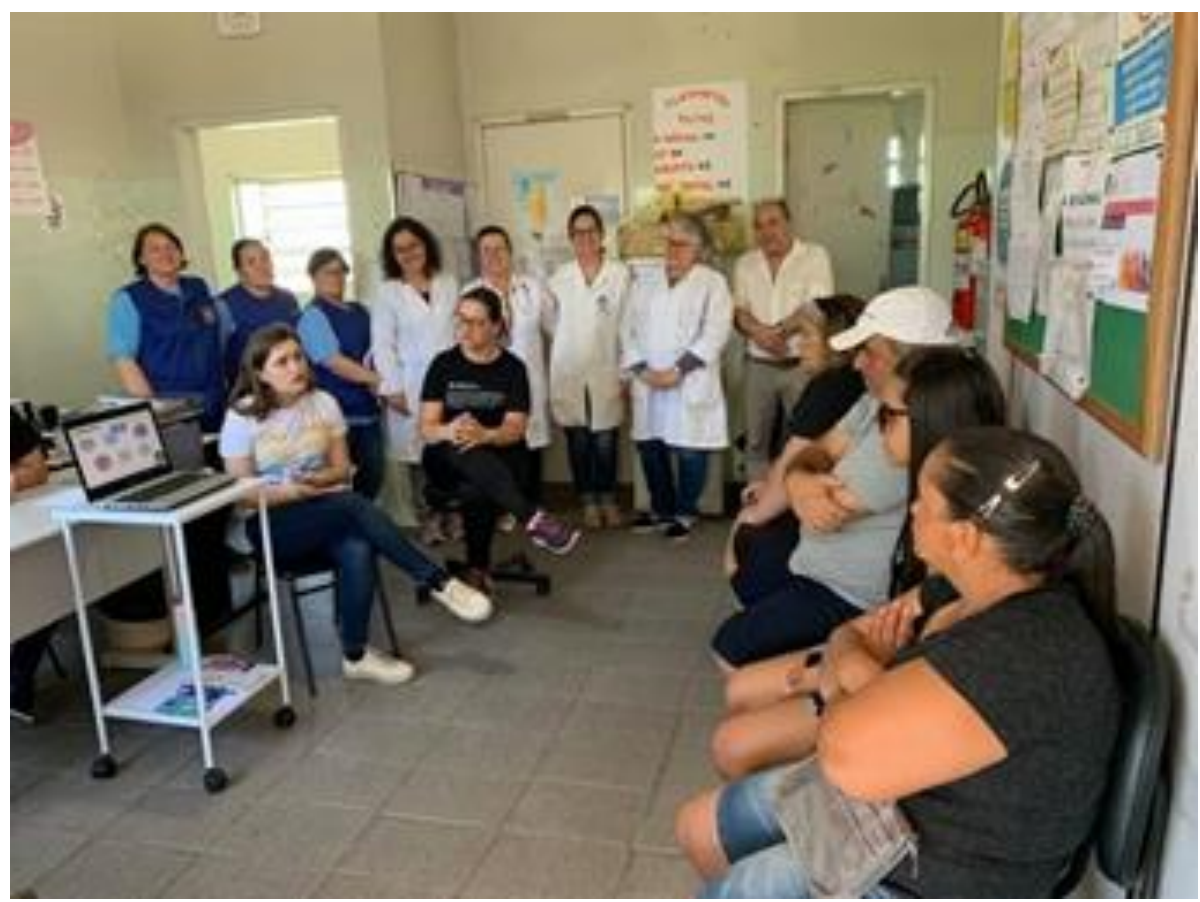

Fonte: Dados desta pesquisa.

Durante as atividades, pôde-se perceber o envolvimento dos participantes no que se refere aos tipos de violência e aos direitos das mulheres vítimas de agressão por parte do parceiro. A grande maioria dos usuários compreendia a gravidade do tema e a necessidade em se tomar atitudes que acabem com o ciclo da violência. É de amplo conhecimento os locais onde devem ser denunciados os casos de violência, bem como a Lei Maria da Penha (Lei no 11.340/2006), suas aplicabilidades e vulnerabilidades. Embora se perceba o conhecimento da referida lei, uma parte dos participantes ainda atribui que a lei ampara tanto homens quanto mulheres em situação de violência doméstica. Durante os encontros, procurou-se esclarecer as diferenças entre uma lei exclusiva para as mulheres e as leis que são atribuídas a outras formas de violência.

Uma pesquisa realizada em Minas Gerais com 33 mulheres identificou unanimidade quanto ao conhecimento sobre a Lei Maria da Penha. Ainda, 97\% delas consideraram que a criação de uma lei específica para proteger a mulher é essencial para a segurança das mulheres (ANDRÉ, 2020). Após quatorze anos de sua implementação, a Lei Maria da Penha já se tornou um instrumento popularizado no País, e o número de denúncias de ameaças e agressões, infelizmente, aumentou consideravelmente nos últimos anos (SOUZA et al., 2018). 
Ao final da ação, buscando tornar o grupo de pessoas presentes multiplicadores do conhecimento, foi entregue panfletos informativos acerca dos tipos de violência, bem como endereço, telefone e e-mail para contato dos locais relacionados ao combate à violência no município do Rio Grande (Figura 3). A participação do indivíduo é fundamental, pois favorece um processo de conscientização sobre as formas de cuidar de si e de outros, abrindo caminhos para promover a saúde e a cultura da paz (DEMARCHI; GOUVEA; SOUSA, 2017).

Figura 3 - Panfleto (frente e verso)

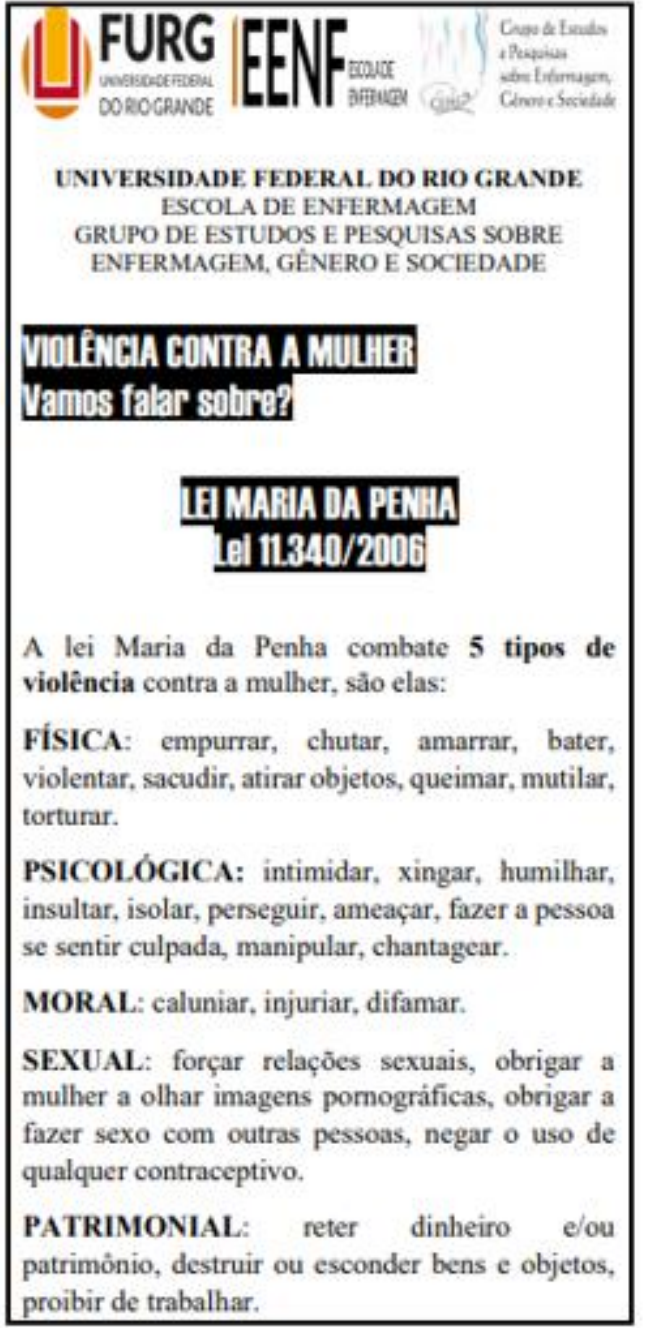

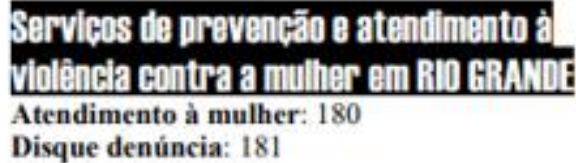

Delegacia Especializada de Atendimento à Mulher/DEAM: Marechal Floriano, 42. Tel. (53) $3237-4884 ;$ ( 53 ) $3231-2043$

Centro de Referência Especializado de Assistência Social/CREAS: Rua General Câmara, 88. Tel.: (53) 3231-1940

Centro de Referência de Assistência Social/CRAS:

CRAS Cidade de Agueda: Av, Antônio Uslenghi Dante Dapuzzo. Tel: (53) 3232-1366

CRAS Dra, Lúcia Nader: Rua 6, s/n - Santa Rita de Cássia. Tel.: (53) 3230-4140

CRAS Hidráulica: Rua Altamir de Lacerda, 904.

Tel.: (53) 323I-4379

CRAS Volante: Rua Virgilio Porciúncula, 477 -

Vila da Quinta. Tel. (53) 3239-1529

CRAS Zona Portuária: Rua Dom Pedro II -

Getúlio Vargas. Tel.: (53) 3233-1370

Defensoria Pública: Av, Silva Paes, 333. Tel. (53) $3232-3148$

Serviço de Saúde Especializado para o Atendimento dos Casos de Violência Contra a Mulher: Hospital Universitário. End.: Visc. de Paranaguá, 102. Tel.: (53) 3233-8800

\section{SAMU: 192}

Bembeiros: 193

Polícia civil: 197

Brigada militar: 190

Fonte: Dados desta Pesquisa. 


\subsection{Importância da atividade e da temática abordada}

A análise da ação de Extensão se deu por descrição detalhada das atividades e avaliação dos participantes, a qual obteve um retorno positivo, visto que a maioria dos participantes se mostraram satisfeitos com a atividade ofertada e sugeriram outras ações voltadas tanto ao tema da VCM quanto às questões de gênero, conforme ilustram as falas abaixo:

[...] acho mais que necessário que atividades sejam realizadas nos postos de saúde, esclarecendo alguns fatos, pois muitas mulheres não têm acesso ainda, em pleno século XXI. (Participante 1)

Foi bem apresentada e especificada com exemplos e demonstrações para que nós mulheres possamos entender mais do assunto e estarmos presentes e ativas nas coisas que acontecem hoje em dia." (Participante 3)

Destaca-se que, apesar das ações serem voltadas aos homens e mulheres usuários(as) das ESF, em muitas unidades a participação delas foi unânime. Os homens que participaram, mesmo que em minoria, mostraram-se interessados pela temática, fazendo questionamentos e contribuições. Porém, quando comparado com as mulheres, pôde-se perceber que os homens ficaram desconfortáveis em alguns momentos, como na discussão sobre gênero, patriarcado e reprodução da violência.

Os conceitos freireanos são oportunos para o desenvolvimento de um trabalho educativo voltado à promoção da saúde, permitindo a identificação de conflitos e contradições que representam uma situação existencial de saúde de uma determinada realidade vivenciada por homens e mulheres (DALMOLIN; HEIDEMANN, 2020). Logo, a educação em saúde possibilita a reflexão e análise de determinadas práticas, gerando um processo de mobilização para mudanças (DEMARCHI; GOUVEA; SOUSA, 2017). Para Paulo Freire, a pessoa empoderada é aquela que realiza, por si mesma, as mudanças necessárias e ações que a levam a evoluir e se fortalecer (CESARINO; SCIARRA, 2017).

Assim, é de suma importância dar visibilidade aos casos de violência e buscar maneiras de erradicá-la por meio de intervenções, dentre as quais a prática extensionista se destaca. Por meio dela é possível realizar reflexões e discussões sobre a VCM, bem como das questões de gênero que dela decorrem. Com as atividades extensionistas, abrem-se novos caminhos para o enfrentamento das diferentes manifestações de violência, além de 
promover a conscientização dos participantes acerca de suas atitudes frente a essa problemática e seu papel na sociedade (PIBER, 2017).

\subsection{Reflexões para além da atividade de Extensão}

Extrapolando as ações de Extensão, como sugestões, os participantes identificaram a falta da responsabilização do Estado frente à VCM, o que demonstra a insatisfação com o cenário atual:

Que nossos políticos sejam mais atentos a essas mulheres, fazendo com que essa covardia seja punida. (Participante 1)

Diante disso, o Estado precisa assegurar Políticas Públicas que incentivem as mulheres a romper com o ciclo de violência, incluindo ações de prevenção da violência desde a infância, e, também, de punição justa aos autores que, de certa forma, ignoram o poder público (ANDRÉ, 2020). Mesmo com os avanços assegurados pela Lei $\mathrm{n}$ ㅇ 11.340 , constata-se que as mulheres continuam sendo ameaçadas mesmo após a denúncia e as medidas de afastamento. Essa situação corrobora para que as mulheres tenham suas vidas permeadas por sentimentos constantes de insegurança e para o descrédito frente às Políticas Públicas (SOUZA et al., 2018). 0 empoderamento também é um processo social, cultural, psicológico e político, por meio do qual os indivíduos são capazes de expressar suas necessidades e idealizar estratégias para a tomada de decisões, alcançando ações políticas, sociais e culturais para atender essas demandas (CESARINO; SCIARRA, 2017).

\subsection{Sugestões para futuras atividades de Extensão}

Os participantes enfatizaram a necessidade de ações de Extensão em outros ambientes e com diferentes públicos, além de palestras destinadas às famílias em situação de violência.

Gostaria de atividades como essa em espaços maiores e com maior frequência, não só nas Unidades de Saúde, mas nas escolas onde estão sendo formados futuros cidadãos. (Participante 2)

Que tenham palestras para ajudar as famílias. (Participante 3) 
Assim, fica evidente à importância da intersetorialidade, objetivando não apenas o enfrentamento à violência através de iniciativas de punição, mas de prevenção e conscientização, subsidiando mudanças sociais que visem à garantia e ampliação dos direitos das mulheres por meio de ações coletivas de diferentes setores, tais como a saúde, a segurança pública, a justiça, a educação, entre outros e, assim, apresentar intervenções que acabem com as desigualdades e combatam as discriminações de gênero e a violência contra as mulheres (SOUZA et al., 2018).

Para que a transformação não fique apenas no campo do sonho e da utopia, é necessária a ação, ação coletiva para o alcance do sonho coletivo. A violência é uma problemática, infelizmente, estabelecida, reproduzida e, por vezes, naturalizada, porém quando essa realidade gera estranhamento, ela também provoca reflexão no sentido de melhor compreendê-la e reconhecê-la como injusta, como uma situação-limite. Assim, buscam-se alternativas coletivas para fazer face ao que está posto e aos contextos que a produzem (PARO; VENTURA; SILVA, 2020).

3.5 Dúvidas que permaneceram: clareando ideias

Pensando nos participantes que poderiam ser mais tímidos ou se sentirem desconfortáveis em questionar dentro do grupo, abriu-se um campo em branco para que pudessem colocar suas dúvidas. A maioria relatou não apresentar dúvidas, mas dois participantes pontuaram suas dúvidas que permaneceram após a atividade de Extensão.

Fiquei com dúvida quanto à denúncia. (Participante 5)

Tenho dúvida em relação às violências que acontecem com mulheres jovens, entre 15 e 20 anos, que o Conselho Tutelar às vezes não se responsabiliza. (Participante 6)

Durante a explanação da temática, abordou-se a diferença entre denúncia policial e notificação compulsória, uma vez que esta última é uma responsabilidade legal dos profissionais de Saúde e se diferencia da denúncia por não haver o envolvimento judicial, mas ser de caráter epidemiológico e que, portanto, propicia a elaboração de Políticas Públicas (MARTINS et al., 2018). Por sua vez, a denúncia pode ser realizada por qualquer indivíduo, tanto no endereço fixo das Delegacias Civis e Delegacias Especializadas de Atendimento à Mulher quanto pelos contatos via telefone, tais como o 180 (atendimento à mulher) e o 181 (disque denúncia) (VIEIRA; GARCIA; MACIEL, 2020). 
Quanto ao Conselho Tutelar, este não foi abordado durante as ações, porém cabe a esse órgão a proteção de crianças e adolescentes diante das situações de violação de direitos, seguindo os preceitos da Lei no 8.069 de 1990, que dispõe sobre o Estatuto da Criança e do Adolescente (ECA). 0 ECA determina a obrigatoriedade da denúncia de todos os casos suspeitos ou confirmados envolvendo castigo físico, tratamento cruel ou degradante e maus-tratos contra crianças e adolescentes aos Conselhos Tutelares locais, sendo, então, uma responsabilidade desse serviço (PLATT; GUEDERT; COELHO, 2021).

3.6 Avaliação das ações pelas extensionistas: aprendizagem a partir da experiência e do sentido

Acredita-se que as atividades de Extensão permitiram aplicar na prática os conhecimentos das acadêmicas, que também passaram a conhecer melhor a realidade social dos participantes e, assim, valorizar todo aprendizado e as oportunidades promovidas pelo ensino acadêmico. Sendo assim, o benefício é mútuo, tanto para os estudantes quanto para a comunidade, e o evento torna-se motivo de exaltação na medida em que se pode ter conhecimento das vidas que serão transformadas a partir da vivência que se dá por meio da Extensão. Logo, tal fato reforça a possibilidade do método oportunizar, na prática formativa, um movimento de reflexão individual e construção do conhecimento compartilhado, pautado na troca de experiências (ARAÚJO et al., 2018).

No entanto, deve-se destacar a baixa adesão e procura dos usuários para tratar sobre o tema. Foi necessário usar os dias de grupos preexistentes dentro das unidades para agendar a realização da ação de Extensão, permanecendo o critério de livre demanda, de modo que todo e qualquer usuário que tivesse vontade e/ou disponibilidade em participar era bem-vindo. Das nove ESF, enfatiza-se que em duas não houve nenhum participante. Ainda, cabe ressaltar que para divulgação da ação extensionista muitas unidades contaram com o trabalho das Agentes Comunitárias de Saúde (ACS) e da divulgação nas mídias sociais (grupos de WhatsApp). Assim, não se pode afirmar se a baixa procura foi devido ao desinteresse, medo ou até mesmo por não possuírem dúvidas sobre o tema.

Há de se considerar, ainda, outros fatores que dificultam a busca de suporte no sistema de apoio familiar e comunitário, tais como a vergonha, o medo e as ameaças por parte do agressor, o que impede o rompimento com a situação abusiva. Porém, diversas experiências de grupos reflexivos têm demonstrado que, apesar das dificuldades, espaços de acolhimento e escuta, de trocas de experiências e reflexões sobre as diversas formas 
de violência podem transformar o pensar e o agir frente a situações conflituosas (PIBER, 2017; CAMPOS; TCHALEKIAN; PAIVA, 2020).

Foi possível visualizar equipes preocupadas com o número de casos de violência na região de abrangência e com o desenvolvimento de atividades voltadas ao tema. Inclusive as dúvidas desses profissionais frente a essa problemática puderam ser esclarecidas. 0 vínculo estabelecido com a Unidade e sua equipe fortalece a ideia sobre a necessidade de disseminação de informações sobre temáticas polêmicas e atuais. Por outro lado, também se percebeu a falta de participação e envolvimento de algumas equipes com a ação de Extensão. Embora essa não seja uma atribuição dos profissionais, o envolvimento e incentivo desses é um grande aliado na participação dos usuários e no desenvolvimento das ações.

Nessa perspectiva, entende-se que o profissional de Saúde deve ser e estar capacitado para atuar na prevenção e resolutividade do problema. Sua colaboração para o rompimento do ciclo da violência é de vital importância, evitando que casos simples se tornem mais graves. Junto a isso, o profissional deve conhecer as articulações dos serviços em rede para dar maior fluidez e eficácia no atendimento. No entanto, há dificuldade de abordagem do tema frente aos usuários da Atenção Básica, de modo que a violência é pouco identificada nos serviços de Saúde e, logo, subnotificada (BAPTISTA et al., 2015). Essa dificuldade é identificada na literatura como um despreparo dos profissionais de Saúde, verificado na frágil formação acadêmica no que se refere à violação de direitos como um todo, tendo em vista que estes temas são considerados pouco essenciais durante a formação (FEITOSA et al., 2017).

Destaca-se que, atualmente, as equipes se encontram com inúmeras demandas, sobrecarga de trabalho, falta de profissionais e estrutura física inadequada para realização de grupos e rodas de conversas. Quanto ao espaço físico das unidades, observou-se, durante as ações, que a maioria não possui um local específico para a realização de atividades como essas ou semelhantes, de forma que, em grande parte das ESF, os encontros foram realizados em um local próximo à Unidade, como na Associação de Moradores ou em um salão de uma igreja do bairro.

Somado a isso, não foi possível concluir a aplicação das atividades de Extensão em todas as Unidades de Saúde do município devido ao período de isolamento social imposto pela Pandemia da Covid-19. Apesar de todo esse contexto, ressalta-se a necessidade de capacitar acadêmicos e profissionais para atuar no atendimento às pessoas em situação de violência na comunidade, uma vez que a maneira mais adequada para trabalhar educação em saúde é através do diálogo com os usuários. Desta forma, é necessário ampliar as discussões que viabilizem uma mudança na forma como a Extensão 
é vista, possibilitando que ela seja um momento de aplicação da teoria e do conhecimento científico adquirido na Universidade (RIBEIRO; PONTES; SILVA, 2017).

\section{CONSIDERAÇÕES FINAIS}

A ação de Extensão se mostrou importante para a formação acadêmica, pois contribuiu na interação com a comunidade, aproximando a vida universitária da realidade social dos usuários, e proporcionou uma prática de educação em saúde frente a um tema tão complexo. Acredita-se que as pessoas usuárias da ESF podem conviver e sofrer com diversas situações de violência, em especial contra a mulher. Assim, espera-se que os resultados deste Estudo possam contribuir para a mudança gradual e sistemática, uma vez que a Universidade é um dos canais possíveis para o rompimento do ciclo de violência, desenvolvendo ações dentro desta comunidade e, logo, cumprindo com o seu compromisso social.

Embora o tema seja de extrema relevância e importância, o estudo mostrou que existem dificuldades para se trabalhar com o tema da VCM nas Unidades de Saúde, tais como a baixa adesão e participação de usuários e profissionais e a falta de espaço físico para essas atividades. No entanto, os participantes das atividades mostraram-se envolvidos e agradecidos pela abordagem da temática, demonstrando conhecimento sobre as formas de violência, os direitos das mulheres em situação de violência, os locais de atendimento e a existência da Lei Maria da Penha e suas aplicabilidades e fragilidades.

Acredita-se que as atividades de educação na sociedade são essenciais para a mudança de comportamentos agressivos. As ações de Extensão vêm ao encontro com essas mudanças, pois todo conhecimento técnico-científico adquirido dentro do meio acadêmico pode ser levado para a comunidade, com uma linguagem clara, dados reais e abordagem sensível. Ressalta-se ainda a importância da disseminação de informações e de conhecimento referentes aos conflitos de gênero que marcam a sociedade brasileira. Assim, faz-se necessário o desenvolvimento de ações semelhantes não somente nas Unidades de Saúde, mas também nos mais variados espaços, como o ambiente escolar.

\section{REFERÊNCIAS}

AMARIJ0, Cristiane Lopes et al. Assimilating the theory and practice of domestic violence: nursing professionals providing primary care for victims. Revista

Enfermagem UERJ, Rio de Janeiro, v. 26, p. 1-7, 2018. DOI:

http://dx.doi.org/10.12957/reuerj.2018.33874. 
ARAÚJO, Bárbara Bertolossi Marta de et al. Paulo Freire's theoretical and methodological framework: contributions in the field of nursing. Revista Enfermagem UERJ, Rio de Janeiro, v. 26, p. e27310, 2018. DOI: https://doi.org/10.12957/reuerj.2018.27310.

ANDRÉ, Taynara Areal Santo. Lei Maria da Penha: reflexões sobre seus 12 anos de existência. Revista do Curso de História da Estácio, Belo Horizonte, v. 1, n. 15, 2020. Disponível

em:<http://periodicos.estacio.br/index.php/historiabh/article/view/8317/47966839>. Acesso em: 19 jan. 2021.

BAPTISTA, Rosilene Santos et al. Sexual violence against women: nurses practice.

Revista da Rede de Enfermagem do Nordeste, Campina Grande, v. 16, n. 2, p. 210-217, 2015. DOI: http://dx.doi.org/10.15253/2175-6783.2015000200010.

BARDIN, Laurence. Análise de Conteúdo. São Paulo: Edições 70, 2011.

CAMPOS, Brisa; TCHALEKIAN, Bruna; PAIVA, Vera. Violência contra a Mulher: vulnerabilidade programática em tempos de SARS-COV-2/COVID-19 em São Paulo. Psicologia \& Sociedade, Recife, v. 32, 2020. DOI: https://doi.org/10.1590/18070310/2020v32240336.

CESARINO, Claudia Bernardi; SCIARRA, Adília Maria Pires. Empoderamento na saúde. Arq. Ciênc. Saúde. São José do Rio Preto, v. 24, n. 3, p. 1-2, 2017. Disponível em:<https://www.cienciasdasaude.famerp.br/index.php/racs/article/view/928/719>. Acesso em: 8 mai. 2021.

CRISOSTIMO, Ana Lúcia; SILVEIRA, Rosemari Monteiro Castilho Foggiatto. A extensão universitária e a produção do conhecimento: caminhos e intencionalidades. Editora: Unicentro, 2017.

DALMOLIN, Indiara Sartori; HEIDEMANN, Ivonete Teresinha Schülter Buss. Integrative and complementary practices in Primary Care: unveiling health promotion. Rev. LatinoAm. Enfermagem, Ribeirão Preto, v. 28, e3277, 2020. DOI: http://dx.doi.org/10.1590/1518-8345.3162.3277.

DEMARCHI, Stephania Mendes; GOUVEA, Maria da Penha Gomes; SOUSA, Susane Petinelli. Paulo Freire in the nursing academic production: a bibliometric study. Revista de Pesquisa Cuidado é Fundamental Online, Rio de Janeiro, v. 9, n. 4, p. 1094-1098, 2017. DOI: 10.9789/2175-5361.2017.v9i4.1094-1098.

FEITOSA, Ariel Luiza Xavier et al. Atendimento à mulher que sofre violência doméstica na Estratégia de Saúde da Família. Congresso Internacional de Enfermagem, Aracajú, v. 1, n. 1, p. 1-4, 2017. Disponível em:<https://eventos.set.edu.br/cie/article/view/6030/2384>. Acesso em: 19 jan. 2021.

FREIRE, Paulo. Pedagogia do Oprimido. Rio de Janeiro: Paz e Terra, 2014. 
GUTMANN, Victoria Leslyê Rocha et al. Social representations of Primary Health Care users about violence: a gender study. Rev Gaúcha Enferm, Porto Alegre, v. 41, 2020. DOI: https://doi.org/10.1590/1983-1447.2020.20190286.

HIRT, Maiara Carmosina et al. Social representations of violence against women for a group of rural elderly. Rev Gaúcha Enferm, Porto Alegre, v. 38, n. 4, 2017. DOI: http://dx.doi.org/10.1590/1983-1447.2017.04.68209.

MACHADO, Maria Elza de Souza et al. Perception of health professionals about violence against women: a descriptive study. Online Brazilian Journal of Nursing, Rio de Janeiro, v. 16, n. 2, p. 209-217, 2017. DOI: https://doi.org/10.17665/1676$\underline{4285.20175596 .}$.

MARTINS, Lidiane de Cassia Amaral et al. Violência de gênero: conhecimento e conduta dos profissionais da estratégia saúde da família. Rev Gaúcha Enferm, Porto Alegre, v. 39, n. e2017-0030, 2018. DOI: https://doi.org/10.1590/1983-1447.2018.2017-0030.

MENDONÇA, Carolina Siqueira et al. Violence and Primary Health Care in Brazil: an integrative literature review. Ciênc. saúde coletiva, Rio de Janeiro, v. 25, n. 6, p. 22472257, 2020. DOI: https://doi.org/10.1590/1413-81232020256.19332018.

MORAES, Juliano Teixeira; FARIA, Rafaela das Graças Santiago; FONSECA, Deborah Franscielle da. Atenção à saúde da pessoa com estomias em um programa de extensão universitária. Caminho Aberto: Revista de Extensão do IFSC, Florianópolis, v. 6, n. 10, p. 85-89, 2019. DOI: http://dx.doi.org/10.35700/ca.2019.ano6n10.p85-89.2435.

OLIVEIRA, Ana Paula Reis de et al. Violência contra a mulher: facilidades e dificuldades relacionadas à atenção multiprofissional. Rev. Saúde Col. UEFS, Feira de Santana, v. 8, n. 54-61, 2018. DOI: https://doi.org/10.13102/rscdauefs.v8.2094.

PARO, César Augusto; VENTURA, Miriam; SILVA, Neide Emy Kurokawa e. Paulo Freire e o inédito viável: esperança, utopia e transformação na saúde. Trab. educ. saúde, Rio de Janeiro, v. 18, n. 1, e0022757, 2020. DOI: https://doi.org/10.1590/1981-7746sol00227.

PATIAS, Naiana Dapieve; HOHENDORFF, Jean Von. Critérios de qualidade para artigos de pesquisa qualitativa. Psicol. Estud, Maringá, v. 24, p. e43536, 2019. DOI: https://doi.org/10.4025/psicolestud.v24i0.43536.

PIBER, Lizete Dieguez. Extensão universitária: discutindo violência de gênero na cidade de Santo Ângelo/RS. Seminário Internacional Fazendo Gênero, p. 1-10, 2017. Disponível

em:<http://www.en.wwc2017.eventos.dype.com.br/resources/anais/1498874079_AR QUIVO_texto_completo_Lizete.pdf>. Acesso em: 20 jan. 2021.

PLATT, Vanessa Borges; GUEDERT, Jucélia Maria; COELHO, Elza Berger Salema. Violence against children and adolescents: notification and alert in times of pandemic. Rev. paul. 
pediatr., São Paulo, v. 39, n. e2020267, 2021. DOI: https://doi.org/10.1590/19840462/2021/39/2020267.

REIS, Rodrigo Oliveira Braga; RAMOS, Ana Sávia Farias; DÁCIO, Dirceu da Silva. Ensino, Pesquisa e Extensão: A articulação das instituições federais de ensino nas ações de políticas públicas de Alto Solimões/AM. Nexus: Revista de extensão do IFAM, Manaus, v. 3, n. 1, p. 1-20, 2017. Disponível

em:<http://nexus.ifam.edu.br/nexus/index.php/Nexus/article/view/154>. Acesso em: 20 jan. 2021.

RIBEIRO, Mayra Rodrigues Fernandes; PONTES, Verônica Maria de Araújo; SILVA, Etevaldo Almeida. A contribuição da extensão universitária na formação acadêmica: desafios e perspectivas. Revista Conexão UEPG, Ponta Grossa, v. 13, n. 1, p. 52-65, 2017. DOI: http://dx.doi.org/10.5212/rev.conexao.v.13.i1.0004.

SOUZA, Tatiana Machiavelli Carmo et al. Lei Maria da Penha: percepções de mulheres em contexto de violência intrafamiliar. Revista Família, Ciclos de Vida e Saúde no

Contexto Social, Uberaba, v. 6, n. 4, p. 724-734, 2018. DOI:

https://doi.org/10.18554/refacs.v6i4.3287.

VIEIRA, Pâmela Rocha; GARCIA, Leila Posenato; MACIEL, Ethel Leonor Noia. Isolamento social e o aumento da violência doméstica: o que isso nos revela?. Rev. bras. epidemiol., Rio de Janeiro, v. 23, n. e200033, 2020. DOI: https://doi.org/10.1590/1980$\underline{549720200033 .}$.

Os autores declaram participação na autoria conforme a Taxonomia CRediT da Casari (vide https://casrai.org/ )

\begin{tabular}{|c|c|c|c|c|c|c|}
\hline Conceituação & Metodologia & Software & Validação & Análise formal & Investigação & Recursos \\
\hline$[2][3][5]$ & {$[2][3][5]$} & & & {$[2]$} & {$[2][3][5]$} & \\
\hline Curadoria & Primeira redação & Revisão/edição & Visualização & Supervisão & Admin. projeto & Financiamento \\
\hline$[5]$ & {$[2][3][5]$} & {$[2][3][4][5]$} & & {$[5]$} & & \\
\hline
\end{tabular}

